\section{Visualization and Assessment of Arterial Progression Quality Using High Resolution Signal Event Data and Measured Travel Time}

Christopher Day1, Ross Haseman', Hiromal Premachandra1, Thomas Brennan', Jason Wasson²,

James Sturdevant ${ }^{2}$, and Darcy Bullock ${ }^{1}$

1: Purdue University; 2: Indiana Department of Transportation
PURDUE

$\begin{array}{llllllllll} & \mathrm{N} & \mathrm{N} & \mathrm{V} & \mathrm{E} & \mathrm{R} & \mathrm{S} & \mathrm{I} & \mathrm{T} & \mathrm{Y}\end{array}$

Paper No. 10-0039 $\mathbf{J} \mathbf{R} \mathbf{P}$

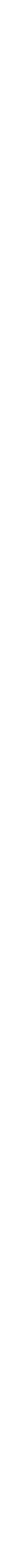


